\title{
BMJ
}

\section{Household ownership and use of insecticide treated nets among target groups after implementation of a national voucher programme in the United Republic of Tanzania: plausibility study using three annual cross sectional household surveys}

Kara Hanson, reader , 'Tanya Marchant, lecturer, ${ }^{1}$ Rose Nathan, senior scientist, ${ }^{2}$ Hadji Mponda, scientist, ${ }^{2}$ Caroline Jones, senior lecturer, ${ }^{1}$ Jane Bruce, research fellow, ${ }^{1}$ Hassan Mshinda, former director, ${ }^{2}$ director general ${ }^{3}$ Joanna Armstrong Schellenberg, reader $^{1}$

'London School of Hygiene and Tropical Medicine, London WC1E 7HT

${ }^{2}$ Ifakara Health Institute, Mikocheni, Dar es Salaam, Tanzania

${ }^{3}$ Tanzania Commission for Science and Technology, Dar es Salaam, Tanzania

Correspondence to: $\mathrm{K}$ Hanson kara.hanson@lshtm.ac.uk

Cite this as: BMJ 2009;338:b2434 doi:10.1136/bmj.b2434

\section{ABSTRACT}

Objectives To evaluate the impact of the Tanzania National Voucher Scheme on the coverage and equitable distribution of insecticide treated nets, used to prevent malaria, to pregnant women and their infants.

Design Plausibility study using three nationally representative cross sectional household and health facility surveys, timed to take place early, mid-way, and at the end of the roll out of the national programme.

Setting The Tanzania National Voucher Scheme was implemented in antenatal services, and phased in on a district by district basis from October 2004 covering all of mainland Tanzania in May 2006.

Participants 6115, 6260, and 6198 households (in 2005, 2006 , and 2007, respectively) in a representative sample of 21 districts (out of a total of 113).

Interventions A voucher worth $\$ 2.45(£ 1.47, € 1.74)$ to be used as part payment for the purchase of a net from a local shop was given to every pregnant woman attending antenatal services.

Main outcome measures Insecticide treated net coverage was measured as household ownership of at least one net and use of a net the night before the survey.

Socioeconomic distribution of nets was examined using an asset based index.

Results Steady increases in net coverage indicators were observed over the three year study period. Between 2005 and 2007, household ownership of at least one net (untreated or insecticide treated) increased from $44 \%$ (2686/6115) to 65\% (4006/6198; P<0.001), and ownership of at least one insecticide treated net doubled from $18 \%(1062 / 5961)$ to $36 \%(2229 / 6198)$ in the same period $(\mathrm{P}<0.001)$. Among infants under 1 year of age, use of any net increased from $33 \%(388 / 1180)$ to $56 \%$ (707/ 1272; P 0.001) and use of an insecticide treated net increased from $16 \%(188 / 1180)$ to $34 \%$ (436/1272; P 0.001$)$. After adjusting for potential confounders, household ownership was positively associated with time since programme launch, although this association did not reach statistical significance $(\mathrm{P}=0.09)$. Each extra year of programme operation was associated with a 9 percentage point increase in household insecticide treated net ownership (95\% confidence interval -1.6 to $20)$. In 2005 , only $7 \%(78 / 1115)$ of nets in households with a child under 1 year of age had been purchased with a voucher; this value increased to $50 \%(608 / 1211)$ in 2007 (P<0.001). In 2007, infants under 1 year in the least poor quintile were more than three times more likely to have used an insecticide treated net than infants in the poorest quintile ( $54 \%$ v $16 \%$; P 0.001 ).

Conclusions The Tanzania National Voucher Scheme was associated with impressive increases in the coverage of insecticide treated nets over a two year period. Gaps in coverage remain, however, especially in the poorest groups. A voucher system that facilitates routine delivery of insecticide treated nets is a feasible option to "keep up" coverage.

\section{INTRODUCTION}

Insecticide treated nets are an effective and cost effective means of preventing malaria, which kills approximately 800000 children under 5 years of age in Africa each year. ${ }^{1}$ The African Summit on Roll Back Malaria — held in Abuja, Nigeria in 2000 — specified that 60\% of at risk groups should use insecticide treated nets by 2005 , a target that was subsequently raised to $80 \%$ by $2010 .^{2}$ Although use of insecticide treated nets remains well below the target level of $80 \%$, recent analysis has shown significant progress in increasing insecticide treated net use by children under 5 years living in stable malaria endemic settings. ${ }^{3}$ Another recent analysis concluded that expanded coverage of insecticide treated nets as part of a multifaceted malaria control strategy was likely to be among the factors contributing to the $35 \%$ decline in mortality among Tanzanian children under 5 years of age between 2000 and 2004 . $^{4}$

Strategies for delivering insecticide treated nets have been controversial, with debates over whether nets 
should be provided through routine health services or through stand alone campaigns, whether they should be distributed through public or private channels, and whether they should be free, partially subsidised, or sold at commercial prices. ${ }^{5-8}$ Concerns have been expressed about whether campaign based distribution strategies (so called "catch up" schemes) that aim to accelerate coverage) will ensure "temporal equity"that is, maintain coverage between campaigns - and sustain coverage over time. ${ }^{910}$ On the other hand, routine distribution strategies that use either the health system or commercial distribution networks might be better placed than campaign strategies to sustain ("keep up") coverage over time. When used alone, however, routine distribution approaches might be associated with a slower increase in coverage and more socioeconomically inequitable distribution. A recent analysis by Noor and colleagues suggested that between 2000 and 2007, coverage of insecticide treated nets increased more in settings with free distribution than in settings that used full cost recovery or highly subsidised distribution through routine delivery channels. ${ }^{3}$ Rapid increases in ownership of insecticide treated nets have been achieved through catch up campaigns in settings where ownership was previously extremely low, such as Niger and Togo, ${ }^{112}$ and Kenya achieved high and equitable levels of coverage by the combination of routine distribution and a mass campaign. ${ }^{13}$ Nevertheless, there has been little evaluation of systems that deliver nets through routine channels.

Table 1 |Stakeholder roles in the national insecticide treated net strategy in Tanzania

\begin{tabular}{|c|c|c|c|}
\hline Programme component & Funder(s) & Stakeholder(s) & Role(s) \\
\hline $\begin{array}{l}\text { Insecticide treated net } \\
\text { steering committee }\end{array}$ & & $\begin{array}{l}\text { Multi-stakeholder; } \\
\text { chaired by the Tanzania } \\
\text { Ministry of Health and } \\
\text { Social Welfare }\end{array}$ & $\begin{array}{l}\text { Oversight of the national } \\
\text { insecticide treated net } \\
\text { strategy }\end{array}$ \\
\hline $\begin{array}{l}\text { Insecticide treated net } \\
\text { coordination unit }\end{array}$ & $\begin{array}{l}\text { Swiss Agency for } \\
\text { Development and } \\
\text { Cooperation }\end{array}$ & $\begin{array}{l}\text { National Malaria Control } \\
\text { Programme with technical } \\
\text { support from the Swiss } \\
\text { Tropical Institute }\end{array}$ & $\begin{array}{l}\text { Coordination of all } \\
\text { elements of the national } \\
\text { insecticide treated net } \\
\text { strategy }\end{array}$ \\
\hline \multirow{3}{*}{$\begin{array}{l}\text { Strategic social marketing } \\
\text { for expanding the } \\
\text { commercial market for } \\
\text { insecticide treated nets in } \\
\text { Tanzania (SMARTNET) }\end{array}$} & $\begin{array}{l}\text { UK Department for } \\
\text { International } \\
\text { Development }\end{array}$ & \multirow[t]{3}{*}{$\begin{array}{l}\text { Population Services } \\
\text { International (non- } \\
\text { governmental } \\
\text { organisation) }\end{array}$} & $\begin{array}{l}\text { Generic promotion of nets } \\
\text { and insecticide re- } \\
\text { treatment }\end{array}$ \\
\hline & \multirow{2}{*}{$\begin{array}{l}\text { Royal Netherlands } \\
\text { Embassy }\end{array}$} & & $\begin{array}{l}\text { Working with } \\
\text { manufacturers to promote } \\
\text { and distribute nets }\end{array}$ \\
\hline & & & $\begin{array}{l}\text { Provision of subsidised } \\
\text { insecticide for packaging } \\
\text { with nets }\end{array}$ \\
\hline \multirow{6}{*}{ Hati Punguzo } & \multirow[t]{3}{*}{$\begin{array}{l}\text { Global Fund to fight AIDS, } \\
\text { Tuberculosis and Malaria }\end{array}$} & $\begin{array}{l}\text { Mennonite Economic } \\
\text { Development Associates } \\
\text { (non-governmental } \\
\text { organisation) }\end{array}$ & $\begin{array}{l}\text { Procurement, distribution, } \\
\text { and redemption of } \\
\text { vouchers }\end{array}$ \\
\hline & & World Vision & \multirow{2}{*}{-Training and promotion } \\
\hline & & CARE & \\
\hline & \multirow{3}{*}{$\begin{array}{l}\text { United States President's } \\
\text { Malaria Initiative }\end{array}$} & $\begin{array}{l}\text { District health } \\
\text { management teams } \\
\text { Health facility staff }\end{array}$ & $\begin{array}{l}\text { Distribution of vouchers to } \\
\text { clinics and to pregnant } \\
\text { women }\end{array}$ \\
\hline & & Retail shops & $\begin{array}{l}\text { Redemption of vouchers } \\
\text { from women }\end{array}$ \\
\hline & & Net manufacturers & \\
\hline
\end{tabular}

The United Republic of Tanzania has been a pioneer in developing delivery systems for insecticide treated nets. In the $1990 \mathrm{~s}$, a number of small scale projects demonstrated the feasibility of distributing nets through community based channels and through maternal and child health services. ${ }^{145}$ More recently, a strategy that uses social marketing combined with a voucher scheme targeting mothers of young children has been shown to be both effective and cost effective ${ }^{16-18}$ In addition, early reports on this approach indicate that the health effects of insecticide treated nets shown in clinical trials can also be achieved under "real life" conditions. The challenge of ensuring regular treatment of nets with insecticide contributed to the development in Tanzania of the first "dip it yourself" insecticide product. ${ }^{19}$

Tanzania is unusual in having a successful net manufacturing sector, with four firms producing 2668152 polyester nets bundled with longer lasting insecticide re-treatment kits and 298996 polyethylene Olyset nets (Sumitomo Chemical Co Ltd, Tokyo) for the domestic Tanzanian market in 2007 (J Miller, personal communication, 2008). The retail distribution network comprises approximately 20000 urban and rural net retailers. In addition, use of antenatal services in Tanzania is high, with $94 \%$ of women receiving antenatal care from a health care professional at least once during pregnancy. ${ }^{20}$

Together, these circumstances influenced the development of the National Insecticide Treated Net Strategy, which provides subsidised nets targeted at vulnerable groups alongside support to the commercial distribution system. ${ }^{21}$ Stakeholders involved in the strategy are shown in table 1. From 2002 until 2007, the strategic social marketing for expanding the commercial market for ITNs [insecticide treated nets] in Tanzania (SMARTNET) project contributed to the development of the commercial market through nationwide generic promotion of insecticide treated nets and insecticide re-treatment. The project also worked with the four net manufacturers to promote and distribute their products and provided subsidised insecticide to them for bundling with untreated polyester nets.

The Tanzania National Voucher Scheme is a targeted subsidy programme that aims to create a stable and predictable demand for insecticide treated nets in even the most remote locations and, in turn, relies on the commercial sector to distribute insecticide treated nets throughout the country. The initial objective of the programme was to achieve $60 \%$ coverage of children under 5 years and pregnant women with insecticide treated nets by 2007. Under the voucher scheme, every pregnant woman who attends antenatal care is eligible to receive a voucher, called "Hati Punguzo" ("discount voucher" in Swahili), that can be used as part payment for an insecticide treated net (a conventional net bundled with a package of insecticide) from any authorised shop. The vouchers carry a fixed value; this was set at 2750 Tanzanian shillings (TSh; £1.37, $€ 1.62, \$ 2.28$ ) from October 2004 to December 2006 and was raised to TSh 3250 in January 2007. A 
woman can purchase any size of net upon production of the voucher and her antenatal care card.

Given that the retail price for a net varies according to where the net is purchased and the size and shape of the net, the remaining amount paid by the voucher holder (the "top up") is variable. In 2006, the mean top up payment was TSh 1149, which implies that on average the voucher provided a subsidy of approximately two thirds the price of a standard $4 \times 6 \mathrm{ft}$ net.

In addition to vouchers, health facilities also distribute free insecticide re-treatment kits to infants when they attend for measles vaccination. In early 2007 a new voucher, funded by the United States President's Malaria Initiative, was introduced for infants attending a measles vaccination clinic.

The Tanzania National Voucher Scheme was initially launched in a small number of districts in October 2004 and reached a national scale in May 2006. By June 2008, 2.47 million pregnant woman vouchers and 369000 infant vouchers had been redeemed. The Global Fund Round 1 grant came to an end in October 2007 and was followed by a Rolling Continuation Channel grant, which is a new mechanism set up by the Global Fund to Fight AIDS, Tuberculosis and Malaria that is available to provide continued funding for well performing grants. ${ }^{22}$ The cost and cost effectiveness of the voucher scheme are presented elsewhere. ${ }^{23}$

In addition to the national level activities of the voucher scheme and SMARTNET, a free net distribution scheme targeted at children under 5 years and linked with the measles vaccination campaign took place in the Lindi and Mtwara regions in August and December 2005, respectively, with funding from UNICEF. ${ }^{24}$ Two of the districts sampled in our surveys were located in these regions. Free nets were also distributed at the same time in Rufiji district, with support from the American Red Cross. In addition, there have always been small scale distributions of free nets by non-governmental organisations and various research projects.

The objectives of this study are to assess the changes in the level and socioeconomic distribution of insecticide treated net coverage over the period 2005-2007, during which the voucher scheme was initiated and taken to national scale, and to examine the link between programme duration and change in household net ownership as a measure of programme impact.

\section{METHODS}

The study uses a plausibility design based on three nationally representative cross sectional household and health facility surveys, timed to take place early, mid-way, and at the end of the roll out of the national voucher programme. ${ }^{25} \mathrm{We}$ compared absolute levels and changes in net coverage in areas with and without the programme over three successive years (2005, 2006 , and 2007) as the programme gradually reached the whole country. A comprehensive monitoring and evaluation plan for the voucher scheme was developed alongside the intervention by a joint team from the Ifakara Health Institute and the London School of
Hygiene and Tropical Medicine. ${ }^{26}$ Household ownership of insecticide treated nets and their use by target groups were the outcomes of interest.

The programme was rolled out gradually across Tanzania between October 2004 and May 2006, starting in districts near to Dar es Salaam and ending with some of the most remote districts in the west of the country. This phased roll out was necessary because of the size of the country and allowed us to compare areas with and without the voucher scheme at three points in time. Mainland Tanzania covers 881000 $\mathrm{km}^{2}$ and the estimated population in 2007 was 39.5 million. ${ }^{27}$ The roll out was determined by programme managers on pragmatic grounds, and it was not feasible or acceptable to randomise districts by roll out phase.

Firstly, we examined aggregate changes in net coverage over time. Secondly, we assessed within district changes in net ownership, rather than changes in absolute levels. These within district changes were compared with the length of time that the programme had been operating in each district to examine whether duration of programme was associated with a larger increase in net coverage. Multivariate analysis was used to control for the presence of other net distribution systems such as the free net distribution campaign that had taken place in three of our study districts. We also controlled for other potential confounders such as the starting level of net ownership and the level of mosquito nuisance in the district. Thirdly, as suggested by Webster et al (Plausibility study designs for evaluation of delivery systems at scale, unpublished paper), we used reported source of net to attribute nets to the voucher system and to assess the degree of penetration of voucher nets over time.

We also collected information about intermediate steps in the programme pathway to provide supporting evidence for the argument that the intervention was being implemented at a reasonable level. A number of steps were necessary in order for the voucher scheme processes to translate into effective coverage: vouchers needed to be in stock; women needed to attend antenatal services; women had to receive and redeem their voucher; and women needed to sleep under the voucher net (fig 1). We used evidence from our surveys about intermediate steps in the programme pathway to inform judgments about programme effect.

This paper reports the findings from the household and facility surveys conducted in 2005, 2006, and 2007. These surveys were designed to produce nationally representative estimates of key indicators of net coverage. Sample size was set to estimate the use of insecticide treated nets among children under 5 years and infants aged 0-11 months (under 1 year) in each district with reasonable precision (plus or minus 10\% for children under 5 years and plus or minus $20 \%$ for those under 1 year) and at national level with correspondingly greater precision (plus or minus $2 \%$ for children under 5 years and plus or minus $5 \%$ for those under 1 year), assuming a coverage level of $50 \%$ and a design effect of two. The surveys were conducted in 21 randomly selected districts (fig 2), stratified by planned date of launch of the scheme. Firstly, 


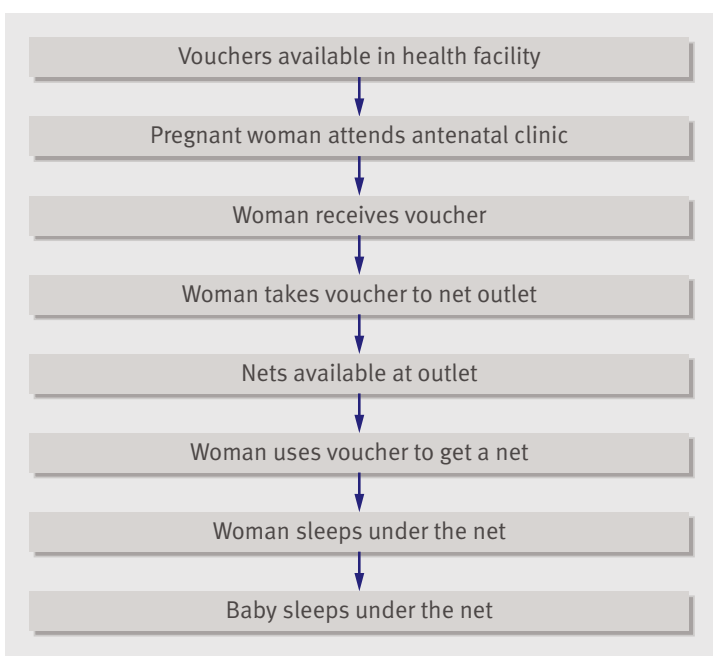

Fig 1 Intermediate steps involved in achieving the programme outcome

districts were sorted into three groups on the basis of launch dates. Secondly, the same sampling fraction (21/113) was applied to each of the three groups to calculate the number of districts to be randomly selected from each. In each district, 10 clusters of 30 households were selected $(\mathrm{n}=6300$ households in total). A cluster was sampled in two stages: firstly, 10 wards within each district were selected, with probability of selection proportional to ward population. Secondly, within each chosen ward, one village ("kitongoji") was selected using simple random sampling. This constituted the primary sampling unit. Within each selected kitongoji, 30 households were chosen using a sampling procedure similar to that used in the Expanded Programme on Immunization, which ensured an equal chance of selection for each household. In subsequent rounds, a kitongoji was selected randomly from within the same wards.

The surveys took place at the same time each year (July-August), immediately after the rainy season. An interviewer administered questionnaire was used to collect information from the household head (number of residents, household characteristics, net ownership and use by all household members), all women aged 15-49 (health service use for current and recent pregnancies, net use in pregnancy), and carers of all children aged under 5 years (net use). A facility survey was conducted at the reproductive and child health centre serving each cluster to collect information about service availability and use.

Analysis was undertaken using Stata v9.0 software (StataCorp LP, College Station, TX); the "svy" commands were used to adjust standard errors for clustering. National level estimates were weighted according to district population in the 2002 Tanzania Population and Housing Census. Weighting made little difference to the final results, however, so unweighted figures are reported here. An index of socioeconomic status was constructed using a principal components analysis on data about housing conditions and household ownership of a selection of assets. ${ }^{28}$ A separate index was constructed for each survey. Households were divided into five equal sized groups (quintiles) according to their score from the principal components analysis. Clusters were classified as rural, semi-urban, or urban by using the same classification employed in the national 2002 census.

The coverage analysis distinguishes between "any net" and "insecticide treated net". In 2005 and 2006, an insecticide treated net was defined as one that had been treated with insecticide within 12 months of the date of the survey. In 2007, a longer lasting insecticide product, K-O Tab 1-2-3 (deltamethrin plus a binder conferring wash resistance; Bayer Environmental Science, Isando, South Africa) was introduced in Tanzania, and there were small numbers of long lasting insecticidal nets in the market and being distributed by small scale projects. For 2007, therefore, the definition of an insecticide treated net included: (1) a conventional net treated with conventional insecticide within the previous 12 months; (2) a conventional net that had ever been treated with longer lasting insecticide; or (3) a long lasting insecticidal net. The treatment status of nets was reported by household heads (for the household ownership indicators), net users (for currently pregnant woman), and mothers or caretakers (for children under 5 years).

In this report we focus on changes in household ownership of nets and use of nets by pregnant women and infants aged 0-11 months (that is, under 1 year of age), although indicators for children under 5 years are also reported. We assessed use of insecticide treated nets by infants under 1 year, rather than by all under 5 years, to trace the impact of the voucher system because this group would be expected to benefit most from a delivery system targeting pregnant women. Also, only a share of children under 5 years old had been exposed to the programme by the end of 3 years. In addition, infants under 1 year of age are at the highest risk of mortality from malaria in high transmission settings. ${ }^{2930}$ Net use was as reported by the relevant respondent (pregnant women reporting for themselves, and carers reporting for their children), and interviewers asked to see all nets that were reported by the household head.

Multivariate regression was used to explore the impact of the voucher scheme on household ownership of insecticide treated nets. The length of time the programme was implemented in each district was measured as the number of days between the launch date and the date of the 2007 survey. This variable was regressed on the change in household ownership of insecticide treated nets at district level between 2005 and 2007. Differences were compared using methods based on the Student's $t$ test, as appropriate for clustered data with a small number of clusters. ${ }^{3132} \mathrm{We}$ controlled for any factors that were constant over time by using the within district change in coverage as the dependent variable. We included covariates to control for three potential confounders that, a priori, were expected to influence the effectiveness of the voucher scheme. These were: (1) the level of net ownership in the district in 2005, which was a proxy for 


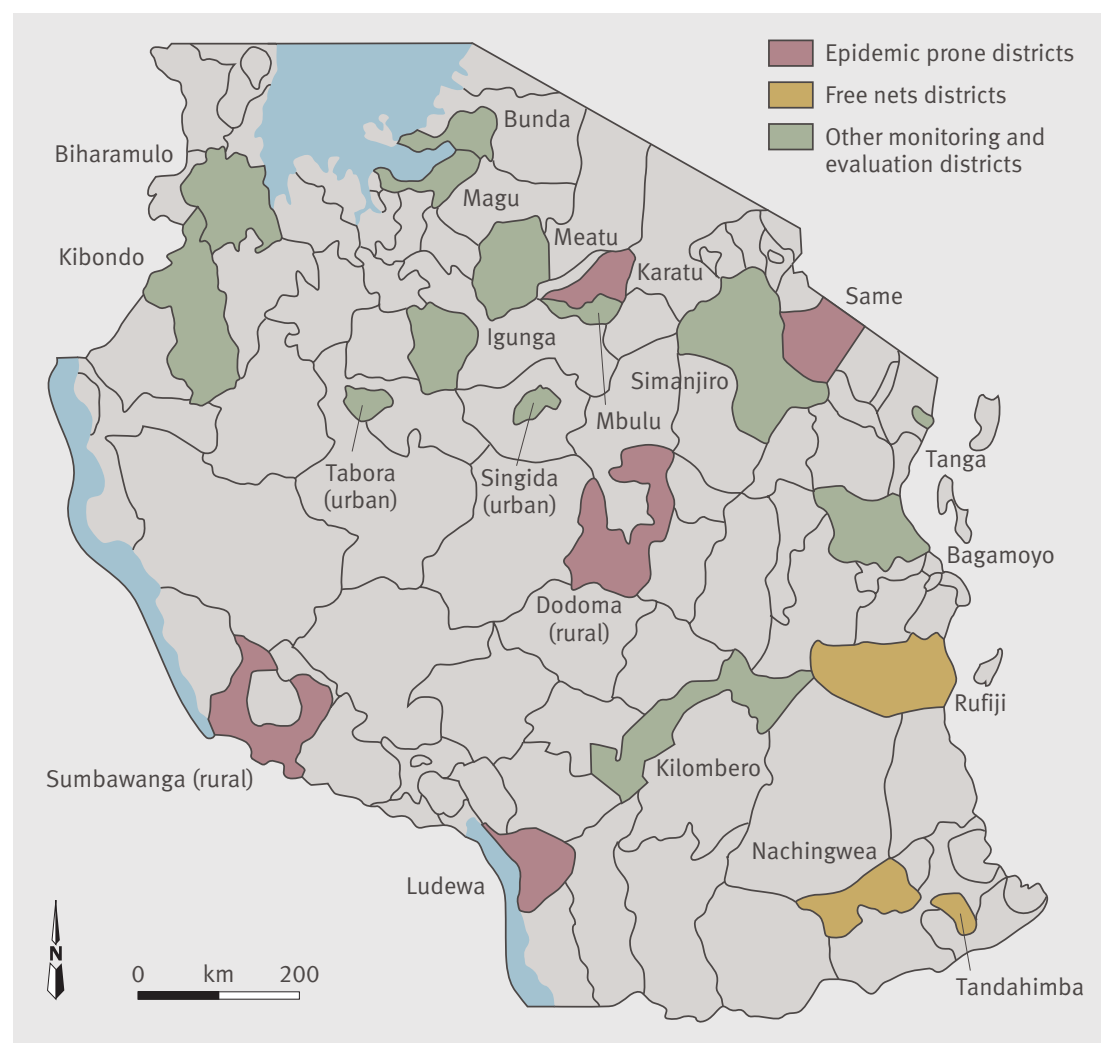

Fig 2 | Tanzania National Voucher Scheme monitoring and evaluation districts

socioeconomic status and allowed a test of whether districts with high starting levels of coverage would see lower programme achievements; (2) whether a district was classified by the National Malaria Control Programme as "epidemic prone," which we would expect to be associated with low mosquito nuisance and, therefore, a lower demand for nets ${ }^{3334}$; and (3) whether the district had been the beneficiary of a free net campaign in 2005. Final model specifications were tested for heteroskedasticity and residual plots were examined.

\section{RESULTS}

National level changes in net coverage

Around 6200 households were successfully interviewed in each of the three surveys (table 2). Refusals were low: 86/6285 (1.4\%), 33/6293 (0.5\%), and 67/ $6265(1.1 \%)$ in 2005,2006 , and 2007, respectively. For women aged 15-49, the number of refusals was $69 / 6733(1 \%)$ in $2005,58 / 6277(0.9 \%)$ in 2006 , and $153 / 7145(2.1 \%)$ in 2007.

Steady increases in national coverage of any net and insecticide treated nets were observed over the study period, measured both as household ownership of at least one net and use of a net the night before the survey (table 3). Household ownership of any net increased significantly from $44 \%(2686 / 6115)$ in 2005 to $65 \%$ $(4006 / 6198)$ in $2007(\mathrm{P}<0.001)$, and treated net ownership increased from $18 \%(1062 / 5951)$ to $36 \%$ (2229/ $6198 ; \mathrm{P}<0.001)$. Over the same period, use of any net among infants under 1 year of age increased from $33 \%$ $(388 / 1180)$ to $56 \%(707 / 1272 ; \mathrm{P}<0.001)$, and treated net use increased from $16 \%(188 / 1180)$ to $34 \%$ (436/ $1272 ; \mathrm{P}<0.001)$. In all three years, use of an insecticide treated net was higher among infants under 1 year than among currently pregnant women or children under 5 . For all indicators, coverage of treated nets was much lower than coverage of any net. Among infants under 1 year, for example, treated net use in 2007 was approximately $60 \%$ of any net use.

\section{District by district changes in net coverage}

Table 4 shows the district level estimates of household ownership of insecticide treated nets in each year. Treated net ownership levels varied widely at the beginning of the programme, ranging from $3 \%$ in Mbulu (8/289) and Sumbawanga (9/298) to over 50\% in Tanga district (142/277). The largest increases in ownership of insecticide treated nets over the period 2005 to 2006 were seen in districts that received free nets in the 2005 vaccination campaign (Nachingwea, Tandahimba, and Rufiji), although ownership of treated nets actually fell in two of these districts between 2006 and 2007. Seven other districts that did not benefit from large scale distribution of free nets saw large increases (in excess of 20 percentage points) in ownership of insecticide treated nets between 2005 and 2007. In 2005, the five districts classified by the National Malaria Control Programme as being "epidemic prone" had a mean level of net ownership of 10\%, compared with $20 \%$ in districts that were not classed as epidemic prone $(\mathrm{P}=0.12)$. In addition, the mean increase in ownership of insecticide treated nets in the epidemic prone districts was only 11 percentage points compared with 20 percentage points in districts that were not classed as epidemic prone $(\mathrm{P}=0.04)$.

Results of the regression analysis indicate that districts with a lower starting level of household ownership in 2005 experienced marginally smaller increases in household ownership over the period 2005 to 2007 ( 0.35 percentage points, $95 \% \mathrm{CI}-0.73$ to $0.03 ; \mathrm{P}=0.07$ ). The change in ownership in epidemic prone districts was 11.2 percentage points smaller than in districts that were not classed as epidemic prone $(95 \% \mathrm{CI}-20.3$ to $-2.2 ; \mathrm{P}=0.02)$. Longer exposure to the scheme was associated with larger increases in ownership $(\mathrm{P}=0.09)$, although this finding is only statistically significant at the $10 \%$ level. Each extra year of exposure to the programme was associated with an additional 9 percentage point increase in insecticide treated net ownership (95\% CI -1.6 to 20$)$.

\begin{tabular}{lccc}
\hline Table 2 | Characteristics of population sampled & \\
& 2005 & 2006 & 2007 \\
$\begin{array}{l}\text { Number of households } \\
\text { interviewed }\end{array}$ & 6199 & 6260 & 6198 \\
\hline $\begin{array}{l}\text { Number of carers of children } \\
\text { under 1 year interviewed }\end{array}$ & 1180 & 1265 & 1317 \\
\hline $\begin{array}{l}\text { Number of carers of children } \\
\text { under 5 years interviewed }\end{array}$ & 5567 & 5815 & 6186 \\
\hline $\begin{array}{l}\text { Number of currently pregnant } \\
\text { women interviewed }\end{array}$ & 779 & 584 & 707 \\
\hline
\end{tabular}


Penetration of voucher nets

There was strong evidence of increased ownership of nets purchased with vouchers in households with target group members compared with households that had no target group members (table 5). In 2005, households with a child under 1 year of age reported that only $7 \%$ of their nets had been purchased with a voucher; this value increased to $50 \%$ in $2007(\mathrm{P}<0.001)$. Voucher penetration in households without target group members remained low over time. The presence of voucher nets in these households could be due to misreporting, leakage of vouchers, pregnancies that did not end with a live birth, or infant deaths.

Inequality in use of insecticide treated nets

The degree of socioeconomic inequality in the use of a treated net by children under 1 year of age is shown in fig 3. Although use of treated nets seems to have increased in all socioeconomic quintiles, large differences remain between the poorest $(\mathrm{Q} 1)$ and least poor (Q5) quintiles. The equity ratio for treated net use improved from 0.11 in 2005 to 0.29 in 2007; however, infants in the least poor quintile were still more than three times more likely to use a treated net as those in the poorest group.

\section{DISCUSSION}

The Tanzania National Voucher Scheme has successfully delivered subsidised insecticide treated nets to vulnerable groups through routine health services and considerably increased the number of mothers and infants using an insecticide treated net, demonstrating that a voucher system is a feasible option for contributing to "keep up" of net coverage. Coverage of nets and treated nets in Tanzania increased over the period 2005 to 2007: household ownership increased by 21 percentage points for any net and doubled from $18 \%$ to $36 \%$ for insecticide treated nets. This is despite the fact that only about $20 \%$ of households would be expected to have a live birth in any one year and, therefore, be eligible for the scheme. Net and treated net use among infants under 1 year and children under 5 years

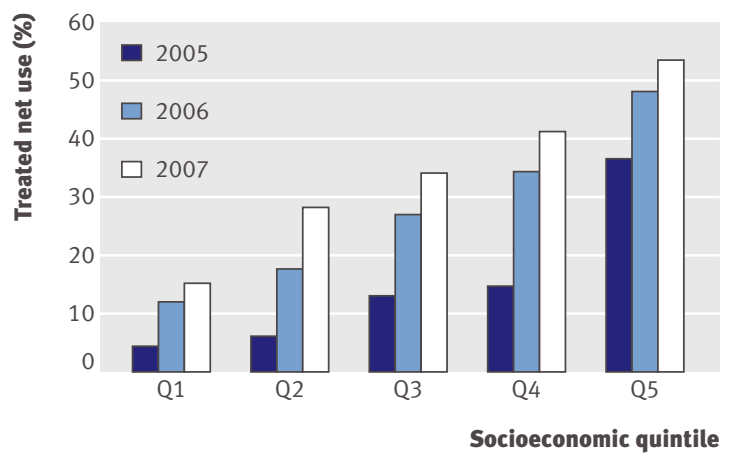

Fig 3 | Insecticide treated net use by children under 1 year old according to socioeconomic status

also increased substantially. Although coverage increased in all socioeconomic groups, clear disparities persist in the socioeconomic distribution of both household ownership of nets and net use by target groups. In 2007, infants under 1 year in the least poor quintile were more than three times more likely to have slept under an insecticide treated net the night before the survey than those in the poorest group.

A number of findings support the conclusion that at least part of the gradual increase in net coverage can be attributed to the voucher scheme. Firstly, the largest improvement in net use was among infants under 1 year of age, who would be expected to benefit most from a voucher scheme targeted at pregnant women. Secondly, districts with longer exposure to the programme tended to have larger increases in household ownership of nets, with a 9 percentage point increase for every year of programme operation. Thirdly, the share of voucher nets in households with target group members (currently pregnant women and infants under 1 year, and indirectly, children under 5 years) increased steadily over the period 2005 to 2007 , whereas in households without a target group member the share of nets reported to have been acquired using a voucher remained low.

Table $3 \mid$ Net ownership and use indicators

\begin{tabular}{|c|c|c|c|c|c|c|c|}
\hline & \multicolumn{2}{|c|}{2005} & \multicolumn{2}{|c|}{2006} & \multicolumn{2}{|c|}{2007} & \multirow{2}{*}{$\begin{array}{c}\text { P value }(2005 v \\
2007)\end{array}$} \\
\hline & $\mathrm{n}$ & $\%(95 \% \mathrm{Cl})$ & $n$ & $\%(95 \% \mathrm{Cl})$ & $\mathrm{n}$ & $\%(95 \% \mathrm{Cl})$ & \\
\hline \multicolumn{8}{|l|}{ Household net ownership } \\
\hline Any net & $2686 / 6115$ & $44(40$ to 48$)$ & $3563 / 6260$ & $57(53$ to 61$)$ & $4006 / 6198$ & 65 (61 to 68$)$ & $<0.001$ \\
\hline Insecticide treated net & $1062 / 5951$ & 18 (16 to 20$)$ & $1711 / 5962$ & 29 (27 to 31$)$ & $2229 / 6198$ & 36 (33 to 39) & $<0.001$ \\
\hline Mean nets per household & $5220 / 6115$ & 0.8 (0.7 to 0.9$)$ & $6939 / 6260$ & 1.1 (1.0 to 1.2$)$ & $8253 / 6198$ & $1.3(1.2$ to 1.4$)$ & 0.006 \\
\hline \multicolumn{8}{|c|}{ Target group members that slept under a net the night before the survey } \\
\hline \multicolumn{8}{|l|}{ Infants under 1 year } \\
\hline Any net & $388 / 1180$ & $33(28$ to 38$)$ & $605 / 1265$ & $48(43$ to 52$)$ & $707 / 1272$ & $56(51$ to 61$)$ & $<0.001$ \\
\hline Insecticide treated net & $188 / 1180$ & 16 (13 to 19$)$ & $350 / 1265$ & $28(24$ to 31$)$ & $436 / 1272$ & 34 (31 to 38) & $<0.001$ \\
\hline \multicolumn{8}{|l|}{ Children under 5 years } \\
\hline Any net & $1533 / 5567$ & $28(24$ to 31$)$ & $2377 / 5815$ & $41(37$ to 45$)$ & $2878 / 6123$ & $47(43$ to 51$)$ & 0.04 \\
\hline Insecticide treated net & $678 / 5567$ & $12(10$ to 14$)$ & $1228 / 5815$ & 21 (19 to 24$)$ & $1601 / 6123$ & 26 (24 to 29$)$ & 0.009 \\
\hline \multicolumn{8}{|l|}{ Currently pregnant women } \\
\hline Any net & $194 / 772$ & $25(21$ to 30$)$ & $198 / 584$ & $34(29$ to 39$)$ & $275 / 707$ & 39 (34 to 44) & $<0.001$ \\
\hline Insecticide treated net & $82 / 772$ & 11 (9 to13) & $103 / 584$ & 18 (14 to 22$)$ & $144 / 621$ & 23 (20 to 27$)$ & $<0.001$ \\
\hline
\end{tabular}


In addition, there is evidence that the intervention was implemented fairly well in health facilities throughout the country and reached the majority of pregnant women (data not shown). Findings from the household and facility surveys about the intermediate processes involved in programme delivery (described in fig 1 ) indicate that more than $95 \%$ of women attended antenatal care at least once, the proportion of facilities with vouchers in stock was high (around 80\% in 2007), the majority of pregnant women attending antenatal care received a voucher (60\% in 2007), and voucher redemption was high throughout the entire period. A 3-4 month interruption in programme funding between May and August 2007 led to interruptions in contracts with implementing agencies and might have been responsible for some variation in programme activity in 2007.

Finally, we have found no evidence to support alternative explanations for this increase in coverage: there was no dramatic improvement in incomes during the study period; the SMARTNET project operated in all districts and, therefore, could not explain the within district differences in coverage improvement; and although nets were delivered through other systems at various points during the study period, the voucher scheme was the only subsidy system operating nationwide and functioning throughout the entire study timeframe.

\section{Strengths and limitations of the study}

We used two different approaches to analyse the changes in coverage over time and to assess whether the changes could be attributed to the voucher scheme. Firstly, we measured at the national level changes in coverage between 2005 and 2007 among different target groups. Statistical tests on these thousands of individual data points provide strong evidence of improved insecticide treated net coverage over time. Moreover, the largest coverage changes occurred among infants, who would be expected to benefit most from the pregnancy voucher scheme. Secondly, we examined the 21 district by district changes in coverage and used regression analysis to relate these changes to programme duration and potential confounders at district level. This approach is much more conservative than the individual level analysis because it reduces the sample size to only 21 data points, one for each district, but has the advantage of focusing on the direct effects of the voucher scheme. The true role of chance in our analysis of the effect of the voucher scheme probably lies between these two extremes.

The analysis of programme impact has a number of limitations. Firstly, the Tanzania National Voucher Scheme is not the only system delivering nets in Tanzania; a number of other delivery mechanisms will have contributed to the increases in coverage observed and it is not possible with this study design to isolate the contributions of each programme. Although the multivariate analysis takes into account the effects of other distribution systems, we cannot rule out potential confounding by other factors that changed during the time the programme roll out occurred. Secondly, for some districts there is no true baseline measure of coverage:

\begin{tabular}{|c|c|c|c|c|c|c|c|}
\hline \multirow[b]{2}{*}{ District } & \multirow{2}{*}{$\begin{array}{c}\text { Date of programme } \\
\text { launch }\end{array}$} & \multicolumn{3}{|c|}{ Household ownership (\% (95\% Cl)) } & \multirow[b]{2}{*}{ P value* } & \multirow{2}{*}{$\begin{array}{l}\text { Epidemic } \\
\text { prone }\end{array}$} & \multirow{2}{*}{$\begin{array}{l}\text { Large free net } \\
\text { campaign } \\
\text { August } 2005\end{array}$} \\
\hline & & 2005 & 2006 & 2007 & & & \\
\hline Dodoma & October 2004 & 16 (10 to 24$)$ & 24 (16 to 35$)$ & 31 (21 to 43$)$ & 0.005 & Yes & No \\
\hline Kilombero & December 2004 & 39 (33 to 47) & $50(42$ to 59$)$ & 53 (46 to 59$)$ & 0.05 & No & No \\
\hline Tanga & December 2004 & 51 (39 to 63) & 59 (51 to 66$)$ & 57 (47 to 66$)$ & 0.56 & No & No \\
\hline Rufiji & February 2005 & 17 (11 to 25$)$ & $47(41$ to 52$)$ & 37 (29 to 46$)$ & $<0.001$ & No & Yes \\
\hline Bagamoyo & March 2005 & 24 (18 to 33) & 30 (20 to 43$)$ & $40(28$ to 53$)$ & 0.10 & No & No \\
\hline Same & April 2005 & 16 (8 to 30$)$ & 25 (14 to 40$)$ & 32 (18 to 52$)$ & 0.17 & Yes & No \\
\hline Singida & April 2005 & 21 (11 to 34) & 36 (26 to 47$)$ & 53 (45 to 61 ) & 0.002 & No & No \\
\hline Nachingwea & May 2005 & 17 (10 to 26$)$ & 44 (36 to 52$)$ & 49 (36 to 62) & $<0.001$ & No & Yes \\
\hline Tabora & June 2005 & 41 (28 to 56$)$ & $47(40$ to 54$)$ & 62 (51 to 72$)$ & 0.04 & No & No \\
\hline Karatu & July 2005 & $8(4$ to 16$)$ & 12 (7 to 21$)$ & 21 (15 to 29) & 0.04 & Yes & No \\
\hline Tandahimba & July 2005 & $5(4$ to 7$)$ & 43 (39 to 47$)$ & $26(22$ to 31$)$ & $<0.001$ & No & Yes \\
\hline Igunga & September 2005 & 7 (2 to 18$)$ & 18 (15 to 23$)$ & 37 (26 to 51$)$ & $<0.001$ & No & No \\
\hline Magu & September 2005 & 31 (22 to 41) & 42 (35 to 49) & 47 (36 to 59$)$ & 0.03 & No & No \\
\hline Bunda & October 2005 & 23 (14 to 34$)$ & 31 (23 to 39) & 53 (45 to 61 ) & $<0.001$ & No & No \\
\hline Biharamulo & November 2005 & 14 (8 to 24) & 17 (12 to 23$)$ & $30(24$ to 37$)$ & 0.006 & No & No \\
\hline Kibondo & November 2005 & 5 (1 to 17$)$ & 15 (11 to 19$)$ & 29 (23 to 36$)$ & $<0.001$ & No & No \\
\hline Simanjiro & December 2005 & 12 (5 to 26$)$ & 20 (9 to 39) & 33 (18 to 53 ) & 0.08 & No & No \\
\hline Mbulu & January 2006 & 3 (1 to 8$)$ & 8 (5 to 14$)$ & 12 (5 to 27$)$ & 0.09 & No & No \\
\hline Meatu & February 2006 & 17 (13 to 23$)$ & 22 (15 to 31$)$ & 29 (19 to 40$)$ & 0.09 & No & No \\
\hline Ludewa & March 2006 & 7 (2 to 20$)$ & 8 (2 to 21$)$ & 11 (6 to 21$)$ & 0.58 & Yes & No \\
\hline Sumbawanga & May 2006 & 3 (1 to 9) & 14 (7 to 26$)$ & 11 (6 to 20$)$ & 0.03 & Yes & No \\
\hline Total & - & 18 (16 to 20$)$ & 29 (26 to 31$)$ & 36 (33 to 39) & $<0.001$ & - & - \\
\hline
\end{tabular}

Data is sorted by programme launch date.

* $\mathrm{P}$ value for design based test for heterogeneity across the three years. 
the first round of evaluation surveys took place in July-August 2005, but the project began activities in October 2004. At the time of the first survey, the distribution programme had launched in 10 of the 21 districts, with a mean time of operation of 4.9 months. The effect of the late baseline measurement is to underestimate the effect of the voucher scheme. Despite these limitations, this evaluation approach does provide significant improvements over the strategies used to evaluate other national programmes, such as the ability to track changes in coverage over a period of a number of years to examine whether coverage increases have been sustained.

\section{Comparison with other studies}

The results reported here come from a strong national level monitoring and evaluation system, developed in collaboration with the National Malaria Control Programme. This strategy contrasts with other more geographically limited monitoring mechanisms, such as that in Kenya, which covered only four districts. ${ }^{13}$ The 2005 estimates of insecticide treated net coverage from our survey are similar to those reported in the 2004/5 Tanzania Demographic and Health Survey, which estimated household ownership of any net to be $46 \%$ and of insecticide treated nets to be $22.6 \% .{ }^{20} \mathrm{~A}$ number of other studies have documented changes in the coverage of any net and treated nets, but few have monitored coverage over an extended time period. One exception is the study by Grabowsky et al, which looked at the combined impact over time of both campaign and routine delivery systems in Ghana. ${ }^{35}$

\section{Conclusions and policy implications}

Despite the significant increases in the coverage of insecticide treated nets recorded in this study, the levels achieved fall far short of the Roll Back Malaria target of $80 \%$ coverage of at risk groups by $2010 .^{2} \mathrm{~A}$ number of implications for the Tanzanian programme thus emerge.

Firstly, as observed elsewhere, ${ }^{36-38}$ the consistent gap between use of any net and use of a treated net suggests an urgent need to improve insecticide treatment of nets. The treatment gap has persisted despite considerable investment by the SMARTNET project in communications activities promoting net treatment and retreatment as well as efforts to work with manufacturers to ensure bundling of all nets with insecticide treatment kits. The Tanzania National Voucher Scheme also delivered free re-treatment kits to infants at the time of measles vaccination, and maternal and child health clinic workers provided health education messages about appropriate use of insecticide treated nets. The difficulty in securing a national consensus on the use of the longer lasting insecticide treatment, which has only received interim (phase 2) approval from the World Health Organization Pesticide Evaluation Scheme, also contributed to the treatment gap. An immediate shift to nets treated with long lasting insecticide would clearly be the best way forward, and this process is actively underway. Meanwhile, a mass free campaign for re-treatment of all existing polyester nets that are more than one year old started in May 2009 and should be completed by early 2010 .

Secondly, although the combination of SMARTNET and the Tanzania National Voucher Scheme has created a functioning system for net distribution, it is clear that a "catch up" campaign is urgently required to raise coverage levels in all socioeconomic groups. This issue has been recognised by the Ministry of Health and Social Welfare in its 2008-2012 proposal to the Global Fund Rolling Continuation Channel, which includes provision for mass distribution of free nets treated with long lasting insecticide to all children under 5 years. This process began in 2008 and will continue through to early 2010 . Combined with the mass re-treatment campaign, coverage levels are expected to be over $80 \%$ among children under 5 years and $50-60 \%$ for the population as a whole by the end of the first quarter of 2010.

The planned catch up campaign should also help to address the third major challenge of the voucher scheme, which is the strong socioeconomic and geographic difference in coverage and use. The barriers to uptake of the voucher scheme among poorer women are likely to be multiple; for example, such women are probably less likely to use antenatal care, are more likely to access antenatal care through outreach services where voucher distribution is less consistent, will have greater difficulty amassing the cash necessary for the top up amount, and might be located further away from shops where vouchers are accepted. Free net distribution will be an important opportunity to increase coverage among the poorest quintile. Significant increases in net use have been observed in the second and third quintiles, however. These

\begin{tabular}{|c|c|c|c|c|c|c|c|}
\hline & \multicolumn{2}{|c|}{2005} & \multicolumn{2}{|c|}{2006} & \multicolumn{2}{|c|}{2007} & \multirow{2}{*}{$\begin{array}{l}\text { Design corrected } P \\
\text { value for difference } \\
\text { across years }\end{array}$} \\
\hline & $\mathrm{n}$ & $\%(95 \% \mathrm{Cl})$ & $n$ & $\%(95 \% \mathrm{Cl})$ & $n$ & $\%(95 \% \mathrm{Cl})$ & \\
\hline $\begin{array}{l}\text { Households with an infant } \\
\text { under } 1 \text { year }\end{array}$ & $78 / 1115$ & 7 (5 to 9$)$ & $460 / 1209$ & 38 (34 to 42) & $608 / 1211$ & 50 (46 to 54$)$ & $<0.001$ \\
\hline $\begin{array}{l}\text { Households with a child } \\
\text { under } 5 \text { years }\end{array}$ & $119 / 3410$ & 3.5 (3 to 5$)$ & $691 / 3683$ & 18.8 (17 to 21$)$ & $1271 / 3795$ & 33.5 (31 to 36$)$ & $<0.001$ \\
\hline $\begin{array}{l}\text { Households with a } \\
\text { currently pregnant woman }\end{array}$ & $47 / 752$ & 6.3 (4 to 9) & $109 / 577$ & 18.9 (16 to 23$)$ & $163 / 691$ & 23.6 (20 to 28$)$ & $<0.001$ \\
\hline $\begin{array}{l}\text { Households with neither a } \\
\text { child under } 5 \text { years nor a } \\
\text { currently pregnant woman }\end{array}$ & $18 / 2520$ & 0.7 (0.5 to 1$)$ & $103 / 2415$ & $4.3(4$ to 5$)$ & $77 / 2220$ & 3.5 (3 to 4$)$ & $<0.001$ \\
\hline
\end{tabular}




\section{WHAT IS ALREADY KNOWN ON THIS TOPIC}

Use of insecticide treated nets is low in many settings, despite their proved effectiveness and cost effectiveness at preventing malaria

Some success has been achieved through "campaign" style distribution systems, but few systems have proved able to deliver nets via routine contact with health services on a national scale

Vouchers are seen as a possible mechanism for delivering public health services, but the few existing programmes have operated on a small scale

\section{WHAT THIS STUDY ADDS}

Use of insecticide treated nets has increased substantially in all groups targeted by the Tanzanian National Voucher Scheme- one of the first to operate at a national scale in a low income setting-although coverage remains inequitable

A voucher scheme is a feasible option for delivery of nets through routine systems

households are also poor by any measure, and it seems that the Tanzania National Voucher Scheme has contributed to increased use of insecticide treated nets in these groups.

\section{Future research questions}

The diversity of epidemiological settings in Tanzania, together with the suggestion that coverage levels have remained low in districts that are "epidemic prone," indicate that there could be merit in linking coverage targets to malaria transmission level, especially in settings where transmission is not homogeneously high. Rapid diagnostic tests were used to check for parasitaemia in the 2008 household survey and will also be used to explore the feasibility of using immunological markers of malaria transmission levels to examine the association between transmission and net use. ${ }^{39}$ Another important issue will be the effect of the 2009 catch up campaign on the routine delivery system. There is a continued need to complement the voucher scheme monitoring and evaluation system with epidemiological evidence about the impact of increased net use on health outcomes. Finally, the financial and institutional sustainability of this approach to routine distribution of nets needs to be monitored and assessed.

We are grateful to the National Malaria Control Programme, the Tanzania National Voucher Scheme implementing partners, the Mennonite Economic Development Associates, CARE, World Vision, and Population Services International for their cooperation in the implementation of the study. We thank Karen Kramer and Christian Lengeler for their important contributions to the overall design of the monitoring and evaluation process, and Christian Lengeler for his helpful comments on the manuscript. Thanks are especially due to Alex Mwita, Renata Mandike, and Nick Brown for their continued support of the monitoring and evaluation process.

Contributors: $\mathrm{KH}$ and RN are principal investigators. $\mathrm{KH}$, TM, RN, HMp, CJ, HMs, and JAS designed the study. HMp and TM oversaw data collection. Analysis was undertaken by JB, TM, and KH. All authors contributed to the interpretation of the data and the drafting of the paper, and all have approved the final version. $\mathrm{KH}$ is the guarantor for the study. Funding: Funds for the 2005 and 2006 surveys were provided by the Ministry of Health through its Global Fund Round 1 grant and the Gates Malaria Partnership. The UK Department for International Development and the Royal Netherlands Embassy provided funds through their grants to Population Services International. The 2007 surveys were funded by the United States President's Malaria Initiative. Although the study was conceived in collaboration with the National Malaria Control Programme, the programme managers had no role in the collection, analysis or interpretation of the data, in the writing of the report, or in the decision to submit the paper for publication.

Competing interests: None declared.

Ethical approval: The study received ethical clearance from the Medical Research Coordinating Committee of the Tanzanian National Institute of Medical Research and the ethics committees of the Ifakara Health Institute and the London School of Hygiene and Tropical Medicine.

1 Rowe AK, Rowe SY, Snow RW, Korenromp E, Armstrong Schellenberg JRM, Stein C, et al. The burden of malaria mortality among African children in the year 2000. Int J Epidemiol 2006;35:691-704.

2 Roll Back Malaria. RBM Global Strategic Plan. Geneva: Roll-Back Malaria Partnership, 2005.

3 Noor AM, Mutheu JJ, Tatem AJ, Hay SI, Snow RW. Insecticide-treated net coverage in Africa: Mapping progress in 2000-07. Lancet 2009;373:58-67.

4 Masanja H, de Savigny D, Smithson P, Schellenberg J, John T, Mbuya C, et al. Child survival gains in Tanzania: analysis of data from demographic and health surveys. Lancet 2008;371:1276-83.

5 Sachs JD. Ending malaria deaths in Africa. Sci Am 2007;297:42-4.

6 Curtis CF, Maxwell CA, Lemnge M, Kilama WL, Steketee RW, Hawley WA, et al. Scaling-up coverage with insecticide-treated nets against malaria in Africa: who should pay? Lancet Infect Dis 2003;3:304-7.

7 Lines J, Lengeler C, Cham K, de Savigny D, Chimumbwa J, Langi P, et al. Scaling-up and sustaining insecticide-treated net coverage. Lancet Infect Dis 2003;3:465-6.

8 Teklehaimanot A, Sachs J, Curtis CF. Malaria control needs mass distribution of insecticidal bednets. Lancet 2007;369:2143-6.

9 Roll Back Malaria Working Group for Scaling Up Insecticide Treated Netting. Scaling up insecticide treated netting programmes in Africa: A strategic framework for coordinated national action. Geneva: WHO, 2002.

10 Lengeler C, DeSavigny D. Programme diversity is key to the success of insecticide-treated bednets. Lancet 2007;370:1009-10.

11 Thwing J, Hochberg N, Vanden Eng J, Issifi S, Eliades MJ, Minkoulou E, et al. Insecticide-treated net ownership and usage in Niger after a nationwide integrated campaign. Trop Med Int Health 2008;13:827-34.

12 Centers for Disease Control and Prevention. Distribution of insecticide-treated bednets during a polio immunization campaign -Niger, 2005. MMWR Morb Mortal Wkly Rep 2006;55:913-6.

13 Noor A, Amin A, Akhwale W, Snow RW. Increasing coverage and decreasing inequity in insecticide-treated bed net use among rural Kenyan children. PLoS Med 2007;4:1341-8.

14 Premji Z, Lubega P, Hamisi Y, Mchopa E, Minjas J, Checkley W, et al. Changes in malaria associated morbidity in children using insecticide treated mosquito nets in the Bagamoyo district of coastal Tanzania. Trop Med Parasitol 1995;46:147-53.

15 Fraser-Hurt N, Lyimo EO. Insecticide-treated nets and treatment service: a trial using public and private sector channels in rural United Republic of Tanzania. Bull World Health Organ 1998;76:607-15.

16 Armstrong Schellenberg JR, Abdulla S, Nathan R, Mukasa O, Marchant TJ, Kikumbih N, et al. Effect of large-scale social marketing of insecticide-treated nets on child survival in rural Tanzania. Lancet 2001;357:1241-7.

17 Hanson K, Kikumbih N, Armstrong Schellenberg JAS, Mponda H, Nathan R, Lake S, et al. Cost-effectiveness of social marketing of insecticide-treated nets for malaria control in the United Republic of Tanzania. Bull World Health Organ 2003;81:269-76.

18 Mushi AK, Armstrong Schellenberg JRM, Mponda H, Lengeler C. Targeted subsidy for malaria control with treated nets using a discount voucher system in southern Tanzania. Health Policy Plan 2003:18:163-71.

19 Miller JE, Jones COH, Ndunguru S, Curtis V, Lines J. A new strategy for treating nets. Part 2: Users' perceptions of efficacy and washing practices and their implications for insecticide dosage Trop Med Int Health 1999;4:167-74.

20 National Bureau of Statistics (Tanzania), ORC Macro. Tanzania Demographic and Health Survey 2004-5. Dar es Salaam, Tanzania: National Bureau of Statistics and ORC Macro, 2005.

21 Magesa SM, Lengeler C, deSavigny D, Miller JE, Njau RJA, Kramer K, et al. Creating an "enabling environment" for taking insecticide treated nets to national scale: the Tanzanian experience. Malar J 2005;4:34

22 Global Fund to Fight Aids, Tuberculosis and Malaria. Rolling Continuation Channel Documents: Frequently Asked Questions. Version 5, 2008. http://www.theglobalfund.org/documents/rcc/ RCC FAQ en.pdf(accessed 23 June 2009).

23 Mulligan J, Yukich J, Hanson K. Costs and effects of the Tanzanian National Voucher Scheme for Insecticide-Treated Nets. Malar J 2008;15:32.

24 Skarbinsky J, Massaga J, Rowe AK, Kachur SP. Distribution of free untreated bednets bundled with insecticide via an integrated child 
health campaign in Lindi region, Tanzania: Lessons for future campaigns. Am J Trop Med Hyg 2007;76:1100-6.

25 Habicht JP, Victora CG, Vaughan JP. Evaluation designs for adequacy, plausibility and probability of public health programme performance and impact. Int J Epidemiol 1999;28:10-8.

26 Hanson K, Nathan R, Marchant T, Mponda H, Jones C, Bruce J, et al. Vouchers for scaling up insecticide-treated nets in Tanzania: Methods for monitoring and evaluation of a national health system intervention. BMC Public Health 2008;8:205.

27 Official Online Gateway of the United Republic of Tanzania. http:// www.tanzania.go.tz (accessed 13 May 2008).

28 Filmer D, Pritchett L. Estimating wealth effects without expenditure data-or tears: an application to educational enrollements in states of India. Demography 2001;38:115-32.

29 Abdullah S, Adazu K, Masanja H, Diallo D, Hodgson A, Ilboudo-Sanogo E, et al. Patterns of age-specific mortality in children in endemic areas of sub-Saharan Africa. Am J Trop Med Hyg 2007;77(Suppl 6):99-105S

30 Korenromp E, Miller J, Cibulskis R, Cham MK, Alnwick D, Dye C. Monitoring mosquito net coverage for malaria control in Africa: possession vs. use by children under 5 years. Trop Med Int Health 2003;8:693-703.

31 Donner A, Klar N. Design and Analysis of Cluster Randomization Trials in Health Research. London: Arnold, 2000.

32 Hayes RJ, Bennett S. Simple sample size calculation for clusterrandomized trials. Int J Epidemiol 1999;28:319-26.
33 Winch PJ, Makemba AM, Kamazima SR, Lwihula GK, Lubega P, Minjas JN, et al. Seasonal variation in the perceived risk of malaria: implications for the promotion of insecticide-impregnated bed nets. Soc Sci Med 1994;39:63-75.

34 Njunwa KJ, Lines JD, Magesa SM, Mnzava AE, Wilkes TJ, Alilio M, et al. Trial of pyrethroid impregnated bednets in an area of Tanzania holoendemic for malaria. Part 1. Operational methods and acceptability. Acta Trop 1991;49:87-96.

35 Grabowsky M, Nobiya T, Selanikio J. Sustained high coverage of insecticide-treated bednets through combined catch-up and keepup strategies. Trop Med Int Health 2007;12:815-22.

36 Brentlinger PE, Correia MA, Chinhacata FS, Gimbel-Sherr KH, Stubbs B, Mercer MA. Lessons learned from bednet distribution in Central Mozambique. Health Policy Plan 2007;22:103-10.

37 Winch PJ, Makemba AM, Makame VR, Mfaume MS, Lynch MC, Premji Z, et al. Social and cultural factors affecting rates of regular retreatment of mosquito nets with insecticide in Bagamoyo District, Tanzania. Trop Med Int Health 1997; 2:760-70.

38 Kazembe LN, Appleton CC, Kleinschmidt I. Geographical disparities in core population coverage indicators for roll back malaria in Malawi. Int J Equity Health 2007;6:5.

39 Corran P, Coleman P, Riley E, Drakeley C. Serology: a robust indicator of malaria transmission intensity? Trends Parasitol 2007;23:575-82.

Accepted: 6 March 2009 